\section{WHAT SHORE-WHALING IS DOING FOR SCIENCE.}

THERE is no group of mammals about which, in recent years, our knowledge has increased with greater rapidity than in the case of the whales. Although for centuries whales have held an important place in the commercial history of the world, until a short time ago almost the only data relating to their habits were drawn from the stories of the men who had hunted them. At best the pursuit incurred great danger and hardship, and the cruises occupied several years. It was, therefore, almost an impossibility for a naturalist to obtain first-hand knowledge of their habits.

But the dearth of accurate information extended not only to their habits, but to their physical characters. Until about twenty-five years ago, there were few naturalists who had an opportunity of seeing, in the flesh, more than a half-dozen or so whales during their entire life. These w e re usually carcases which had been cast upon the beach. Almost invariably these stray examples had been dead for days before they were washed ashore, or came under the notice of a trained scientific observer, and had lost much of their original proportions and colour. A whale's body begins to generate gases at an astounding rate as soon as the animal is dead, and within a very few hours is so swollen and distorted that the true proportions are almost lost. Even naturalists did not always take this fact into consideration and their descriptions and figures a re notable chiefly for their inaccuracy.

It is only within a very few years that the rapidity w $\mathrm{i} t \mathrm{~h}$ which cetaceans change colour: when killed has been generally recognised, and it is a most usual thing to find whales described in scientific papers as "black" which are never black in life. By far the greater number of whales and dolphins have various shades of slate or grey on the upper-parts, and if exposed to the sun for a few hours these portions turn , jet-black. Again, there is, in all cetaceans, great variation in colour and form among individuals of the same species, and whales from the same school or "pod," may differ widely in proportions and general colour. Some may be long and slender, others short and thick: one may have a light grey back and pure white under-parts, while a second, taken from the same herd, is dark slate above and strongly shaded below. Quite naturally when these extremes came under the notice of a man of science, who had, perbaps, seen but three or four whales in his entire life, they were at once judged to be representatives of different species and given new names. This course can scarcely be condemned, for, under existing conditions, it was almost the only one to be followed; but, although it did put on record many valuable NO. 2200 , VOL. 887 facts concerning the history of the animals, it also resulted in multiplying names to such an extent that the work of later investigators in separating the valid from the invalid species has become a herculean task; quite false conclusions were also drawn as to the distribution of the various whales which only a vast amount of labour and study can rectify.

For many years almost all the information concerning the large cetaceans centred about three species, viz., the sperm, the "bowhead," or Greenland right whale, and its smaller relative, the North Atlantic right whale, or "Nordkapper." Other species, of less commercial value, received but comparatively little attention.

In the year 1864, however, Swend Foyn, a Norwegian, invented the harpoon-gun, which was mounted on the bow of a small steamer and fired an iron harpoon having an explosive head, or point, called the "bomb."

With the further development of the harpoon-gun, a

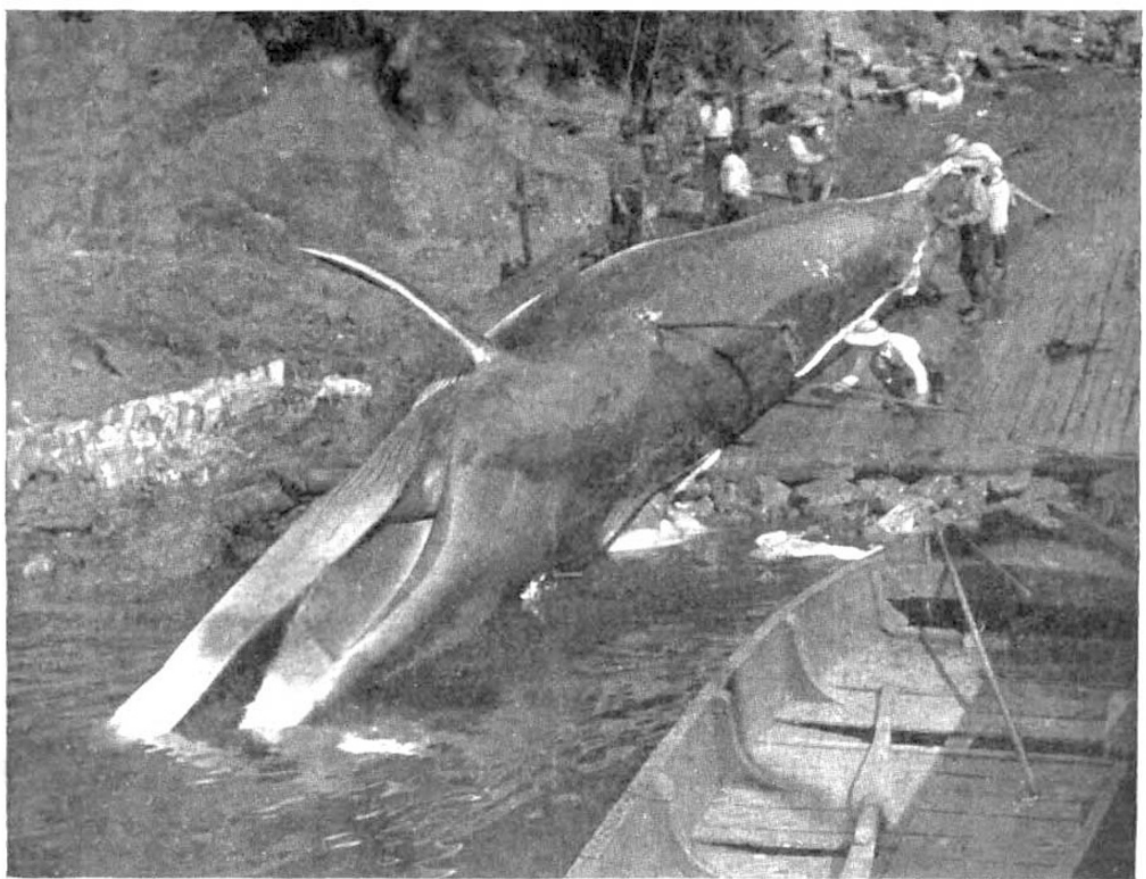

IG. I.-Drawing out a Finner Whale. Japan. the capture of. whales known as "rorquals" or "finners" in sufficient number to warrant the erection of stations at certain points on the shore, near the feeding-grounds of these animals, where they could be brought in, and the huge carcases converted into commercial products. Instead of saving only the oil and baleen (the "whalebone" of commerce) as was the case with the sperm and bowhead whales, which were usually killed far out at sea, it ryas possible also to utilise the flesh, bones, blood, \&c. Previously these whales had been little troubled by the men who hunted in a small boat, and with a hand-harpoon and lance, for the great speed of the animals in the water and their tendency to sink when killed caused them to be let alone by the early whalers; moreover, their blubber was so thin and the baleen so short and coarse, that, if these parts alone were utilised, the animals were not worth the trouble of killing.

In a very ferw years after the harpoon-gun was 
perfected, stations had sprung up on the coasts of Norway in every available place, and later were established on the American shores of the Atlantic. New-

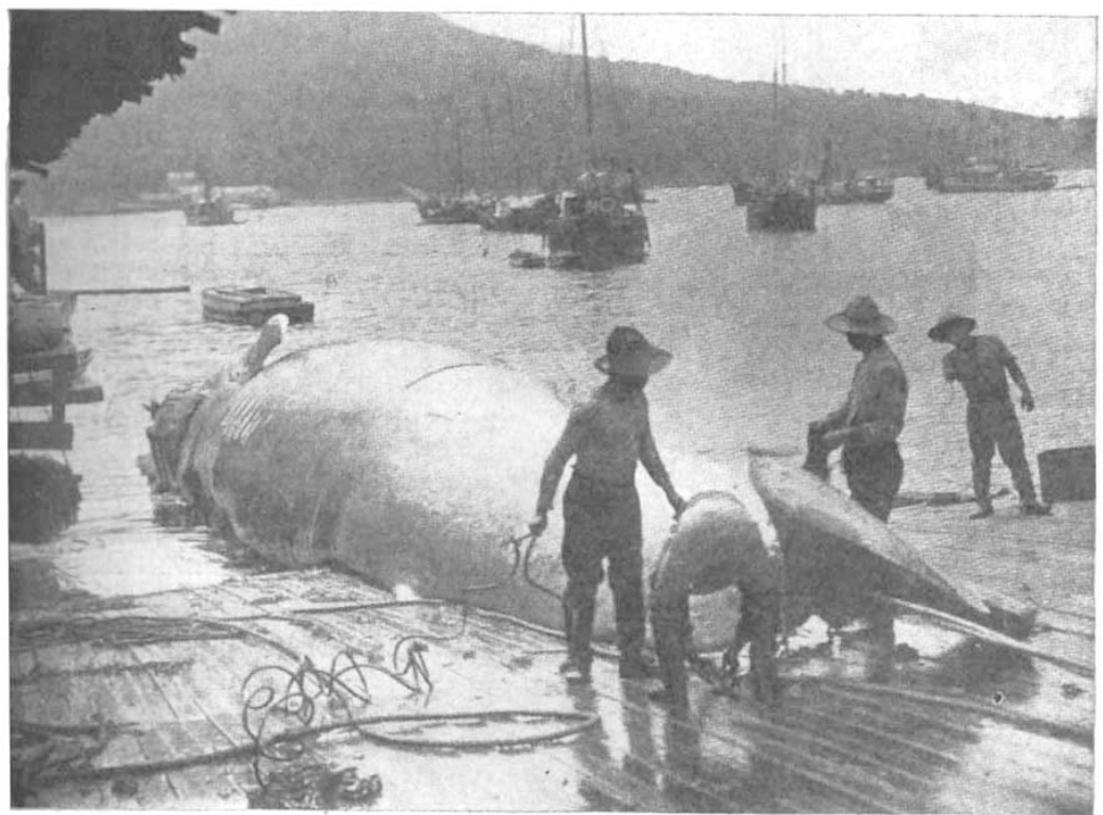

FIG. 2.-Drawing a Blue Whale upon the slip. Japan.

foundland was the first extensive hunting-ground for American whalers, ${ }^{1}$ and only a few years ago as many as eighteen stations were in operation upon that island and in the immediate vicinity.

The great success of the Norwegian methods attracted so much attention that stations were erected in every part of the world where conditions were favourable--in Britis h Columbia, south - eastern Alaska, Bermuda, South America, and the islands of the Antarctic; on the coasts of Japan, Korea, Africa, and Russia. Australia is soon to be invaded, and only a few months ago a company announced its plans for carrying on operations on a large scale in the Aleutian Islands. In New Zealand, humpback whales are being taken in wire nets, and so in nearly every part of the gfobe the pursuit goes on.

The number of whales taken during a season varies greatly with the locality, but at one of the Vancouver Island stations, when I was there in 1908 , 325 were killed in seven months. In a single week twenty-six whales were captured, and on June 30 the ss. St. Law1 About the year 1875 a shore-station was established at Cape Cod, Más.

NO. 2200, VOL. 88$]$ adrift. rence, Captain Larsen, brought in four humpbacks, one blue whale, and one finner. Thus it is obvious that a naturalist who is fortunate enough to remain for some time at one of these shore-stations has before him wonderful opportunities.

Whales are such enormous creatures that the ordinary methods used in the study of other animals cannot be applied to them. Instead of having actual specimens before him for comparison, a naturalist must depend almost entirely upon photographs, notes, measurements, and descriptions. Until shore-whaling began such data were rare and most unsatisfactory. When a whale is "cut in" as it lies alongside a ship it is never possible to see the entire animal at once; it is almost impossible to secure photographs of real value for comparative work; even measurements can be taken only with difficulty, and not without a large percentage of error. Anatomical investigations are ou $t$ of the question, because, as soon as the blubber has been stripped off, the carcase is turned

By the establishment of shore-stations these diffi-

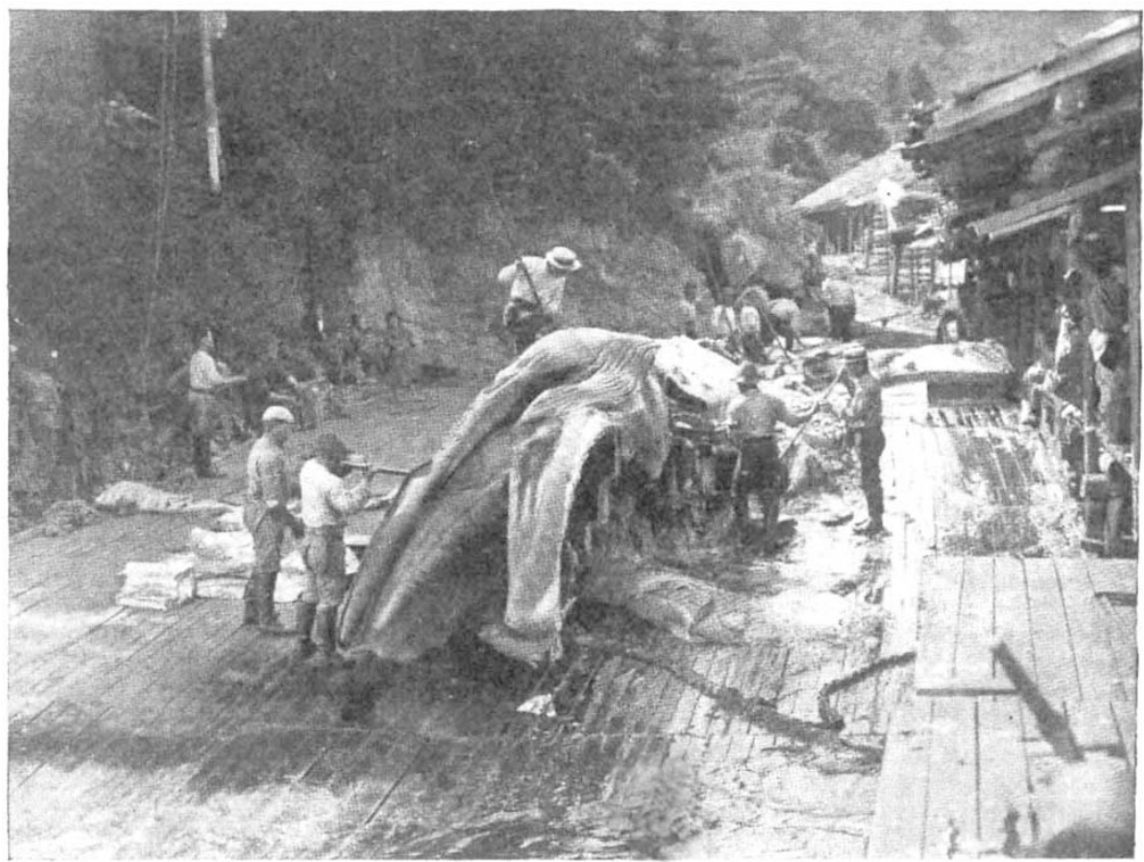

FiG. 3.- "Cutting in" a Right Whale.

culties have been eliminated. The whales are usually drawn entirely out of the water upon a long inclined platform-called the "slip "-where, before the blubber is stripped off, they can be measured, photographed, 
and described. As they are being "cut in" it is possible to make a fairly detailed study of the fresh skeleton and other parts of the anatomy-if the investigator is not afraid of blood and grease.

Moreover, the great number of whales of a single species which are taken facilitates in an unequalled way the study of individual variation in colour and proportions, which evidently is greater among some of the large cetaceans than in any other group of mammals.

The opportunities for the observation and collection of specimens given at the shore-stations, which are located in widely separated parts of the world, has made it possible to investigate the theory, advanced some years ago, that most of the species of large whales are cosmopolitan in distribution; that is, that the humpbacks found in the Atlantic differ in no essential respects from those of the Pacific, and that all belong to a single widespread species.

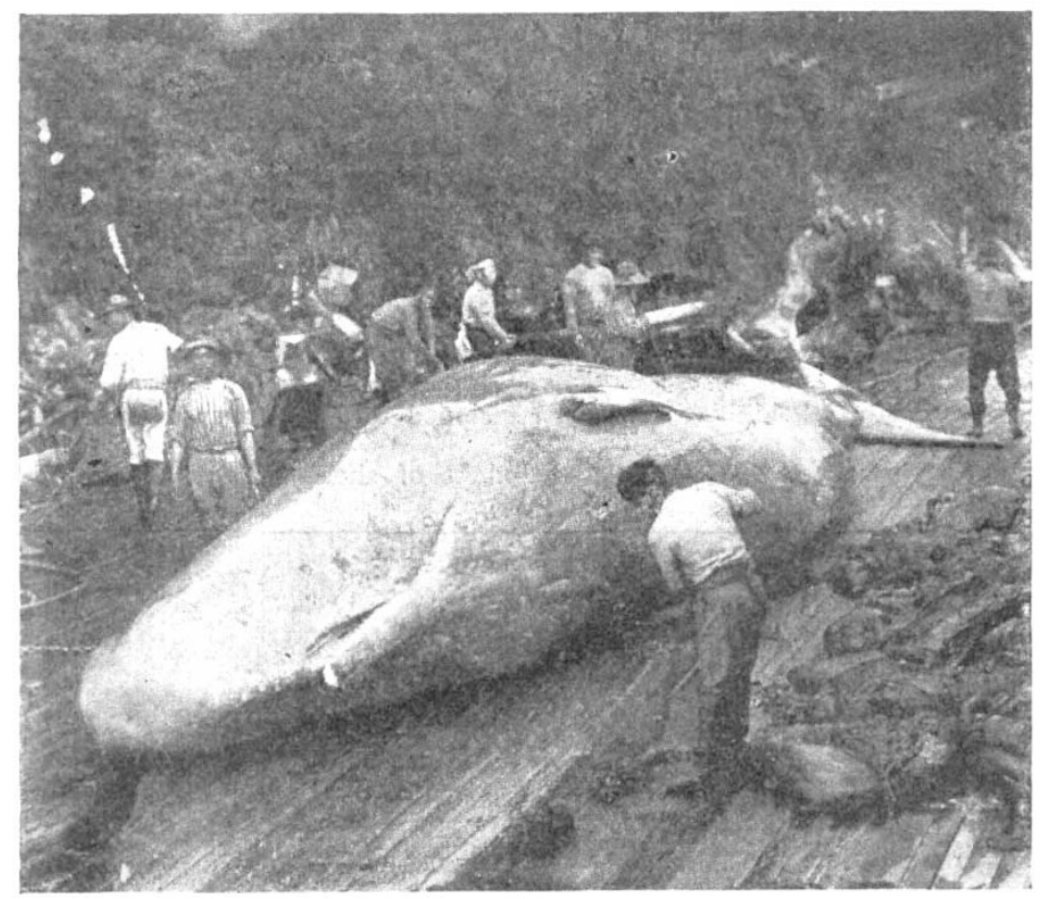

Fil: 4, -A Female Sperm Whale.

Dr. F. W. True, assistant secretary of the Smithsonian Institution, published in $x 904$ a great work entitled "The Whalebone Whales of the Western North Atlantic," in which he discussed the relationship of the Atlantic whales; this book was made possible in its present complete form only by study at the Newfoundland shore-stations. Other shorter papers, too numerous to mention, which have greatly increased our knowledge of these interesting animals, have appeared within the last ten or fifteen years, many of them illustrated with photographs of the whales described.

The Norwegian method of capture has also made possible, and, in fact, comparatively easy, a study of the habits of the large whales.

The ships which hunt from these shore-stations are trim little vessels, about go or soo feet in length, and although they can scarcely be called comfortable, they furnish a not uninviting home for a short stay, if one

NO. 2200, VOL. 88] is a good sailor. From the deck the movements of the whales can be easily seen and studied, and many opportunities are given to secure photographs of living animals. Often such pictures show many things that would otherwise have been unnoticed.

The directors of the shore-whaling companies and the managers of the stations have always been very willing to assist in the study of the animals which form the basis of their industry, and have generously allowed the use of their ships and stations. Not only this, but they have in many instances gone to considerable trouble to secure specimens that could be prepared and presented to museums for the purpose of exhibition and osteological study. Thus the old saying that "It is an ill wind that blows good to no one" applies very decidedly to the whaling industry. It is, however, deeply to be regretted that the wholesale slaughter of whales will inevitably result in their early commercial extinction; but meanwhile science is profiting by the opportunities given for the study of these strange and interesting animals.

Roy C. ANDrews.

\section{THE IMPROVEMENT OF} INDIAN WHEAT.

THE idea prevails that Indian wheats are weak and do not behave well in milling; their chief points of excellence are their great dryness and, owing to the thinness of the bran, the large proportion of flour obtained from them when milled. Mainly as the result of trials, carried out by Messrs. MacDougal in I882, the cultivation of weak, soft white wheats for the purpose of export has been consistently advocated in India. Inquiry amongst the natives has shown, however, that a stronger type of wheat is preferred for their own use.

During the past few years the scientific selection and cultivation of these native strong wheats has been carried out at the Agricultural $\mathrm{Re}$ search Institute, Pusa, on lines similar to the experiments of Prof. Biffen at Cambridge. The results have established beyond doubt that strong, free-milling wheats, but little inferior to Manitoba wheats, can be grown at Pusa. The selected varieties have been submitted to Mr. A. E. Humphries during each of the last three years, and his report, which is included in the bulletin, indicates that they possess great potentialities as regards baking value. They are particularly adapted for special treatment with malt extract and yeast foods, behaving in this respect as Manitoban good-grade wheat produced in a dry season.

From the cultivator's point of view the vield of a variety of wheat is of more importance than the quality of its grain. Much attention has been paid to this point at Pusa, and it has been established that the limiting factors affecting yield in India are the length of the growth period, the water supply, and, particularly in dry districts, the strength of the straw.

1 "The Milling and Baking Qualities of Indian Wheat." By Albert Howard and Gabrielle L. C. Howard. Bulletin No. 22. Agricultural Research Institute, Pusa. Price $8 d$. 